\title{
Gastric Intestinal-Type Adenocarcinoma
}

National Cancer Institute

\section{Source}

National Cancer Institute. Gastric Intestinal-Type Adenocarcinoma. NCI Thesaurus. Code C9157.

An adenocarcinoma of the stomach arising on a background of intestinal metaplasia.

Microscopically, it is characterized by a glandular pattern and it closely resembles a colonic adenocarcinoma. Grossly, it tends to be nodular, polypoid or ulcerated. 